\title{
"Água é vida": política, memória e experiência nos conflitos em torno da mineração em Cajamarca, Peru
}

DOI

http://DX.DOI.ORG/10.11606/ 1678-9857.RA.2021.184476

\author{
Adriana Paola Paredes Penãfiel \\ Universidade Federal do Rio Grande / Rio Grande, RS, Brasil \\ adrianapenafiel@furg.br \\ ORCID: https://orcid.org/0000-0003-4792-2750
}

\author{
Guilherme Francisco \\ Waterloo Radomsky \\ Universidade Federal do Rio Grande do Sul / Porto Alegre, \\ RS, Brasil \\ guilherme.radomsky@ufrgs.br \\ ORCID: https://orcid.org/0000-0002-3756-4286
}

Neste artigo analisamos como se constitui a defesa da vida e das águas em conflitos socioambientais na região de Cajamarca, norte do Peru. A disputa por água tem se tornado nos últimos anos uma questão central da vida das pessoas em uma região que é foco de exploração mineradora e para a qual se utilizam discursos e apelos para evocar os benefícios quanto ao desenvolvimento que ela pode realizar. Ao longo de pesquisa etnográfica se testemunhou o esforço de pessoas e coletivos para defender as águas dos rios, das lagoas e dos canais de irrigação nos Andes em paralelo ao modo como defendem a vida. Ao fazê-lo, articulam memórias, aprendizagens locais e experiências coletivas para romper com os papeis que a ordem política convencional lhes destinou, constituindo criativamente modos próprios de pensar e pôr em prática projetos de vida e resistir à opulência das empresas mineradoras ou às autoridades estatais. 


\section{INTRODUÇÃO'}

Era uma tarde chuvosa o dia 15 de setembro de 2014 quando várias pessoas que haviam participado em lutas contra a empresa mineradora Yanacocha na região de Cajamarca, norte do Peru, se reuniram para o aniversário do dia da libertação do cerro² Quilish. O cerro Quilish foi alvo dos planos de expansão da empresa mineradora Yanacocha ${ }^{3}$, já atuante na região, no ano de 2004 e a população de Cajamarca se opôs a isto de maneira significativa até que fosse declarada a inviabilidade do projeto (Li, 2015, 2016).

Muitos se reuniram em um ponto do caminho entre Cajamarca e Bambamarca para celebrar o acontecimento, com a presença de Máxima Chaupe ${ }^{4}$, o grupo de música Tinkari, ativistas estrangeiros, professores e outros que naquela ocasião simpatizavam com a luta contra o projeto de mineração Conga. Após o conflito em torno do Quilish, Conga foi o mais grave e envolvia a mesma empresa. No momento mais eufórico da celebração, o grupo ocupou a estrada, movimentada pelo trânsito de caminhões, ônibus, carros e vans que vão e voltam de Cajamarca. Pessoas dançavam com a música alta, gritando "Água sim, ouro não!" e entre a música e o som das buzinas os carros em ambos os sentidos se viram obrigados a parar (e esperar). Os gritos dos que ocupavam os veículos eram outros, pois diziam "Conga vai"s, defendendo este projeto, e seguiam aos brados de "voltem a trabalhar, gente ociosa". No entanto, para os manifestantes que celebravam esta importante conquista envolvendo a montanha - emblemática para as populações locais dessa região dos Andes - era preciso não se deixar abalar pelos insultos daqueles que argumentavam em favor da mineração como atividade central para o desenvolvimento econômico. Contrariando a massiva presença dos transeuntes contra o projeto de mineração, no dia seguinte os jornais locais noticiaram que havia pouquíssimos presentes na manifestação. $A$ mídia local questionava ainda a participação de ativistas ambientais de outros países defendendo o argumento do desenvolvimento nacional por meio das atividades mineradoras.

Recuperamos aqui este episódio relacionado ao Quilish porque justamente a provocação da mídia é de que as pessoas não podiam estar perdendo tempo celebrando quando deveriam cuidar dos assuntos de suas competências: as mulheres estavam descuidando seus lares, os camponeses não estavam na roça, e os estrangeiros envolvidos não estavam promovendo a circulação de dinheiro; ao contrário, estavam obstruindo o suposto progresso. $O$ particular desta situação é que, além de dividir o mundo em uma ordem na qual a cada parte cabe sua função e lugar, prima por um ordenamento a partir do trabalho, das identidades, do papel de cada um no desenvolvimento econômico.

No Peru, a experiência com a mineração ocorre há alguns séculos, evidenciada nas inumeráveis bocas de minas e túneis construídos por dentro das montanhas andinas desde a época da colônia. O que hoje se conhece como mineração moderna
1 Os autores agradecem à CAPES e à FAPERCS pelo apoio à pesquisa e também muito especialmente aos(às) pareceristas da Revista de Antropologia pela leitura cuidadosa do trabalho bem como pelas sugestões dadas ao artigo.

$2 \mid 0$ texto apresenta um conjunto de palavras utilizadas localmente, expressões em língua estrangeira e falas das pessoas entrevistadas. Para esclarecimento ao leitor utiliza-se itálico para conceitos locais e expressões estrangeiras (em geral seguidas de tradução na primeira vez em que aparece no texto) Para trechos de entrevistas - bem como citações de referências - de até três linhas são usadas aspas duplas e mantidos no corpo do texto.

3| A mina Yanacocha opera a cerca de $45 \mathrm{~km}$ de Cajamarca por meio da empresa do mesmo nome. Um dos conflitos mais emblemáticos ocorreu no ano 2004 quando a empresa Yanacocha anunciou a expansão das suas operações no cerro (colina) Quilish, a poucos quilômetros da cidade de Cajamarca. Nesse conflito, a inviabilidade da sua exploração foi atingida pelo protesto popular, principalmente pelos residentes da cidade de Cajamarca. A partir de 2010, emergiu outro conflito em torno da região de Conga, que conserva cinco bacias hidrográficas. $\mathrm{O}$ projeto Conga está suspenso em decorrência de uma greve regional realizada em novembro de 2011.

4 | Máxima Acuña de Chaupe recebeu o Prêmio Ambiental Goldman no ano 2016 por defender o direito de residir no seu próprio terreno diante das ameaças da empresa Yanacocha. Máxima reside em frente à lagoa Azul, local de intervenção do projeto de mineração Conga nos Andes peruanos e se tornou o símbolo da luta contra o avanço das empresas mineradoras. minerador vai se realizar. 
apareceu em 1990 e, embora os pressupostos da atividade extrativa fossem continuados, esta modalidade propôs outra dinâmica. Os estudos de impacto ambiental começaram a funcionar quando foram implementadas as normas legais e econômicas para atrair o investimento internacional e resultaram ser instrumento disciplinador de naturezas e pessoas que convivem com elas. As pequenas empresas de mineração que deram prosseguimento aos empreendimentos da colônia declararam-se em crise naquela época por não poderem implementar os requisitos da nova política ambiental.

Assim, com um marco regulatório reformado, empresas de grande aporte de capital, como Yanacocha, apareceram no Peru com uma política de responsabilidade social e começaram a ser bem-vistas ao propor melhorar a qualidade de vida da população a partir do redesenho da natureza. Não sem surpresa que um dos entrevistados durante a pesquisa afirmou com tanta reverência: "Obrigado a Deus que nos deu [ao Peru] tantos recursos para poder explorar. Ea parte técnica nos permite aproveitá-los da melhor forma (Telmo, engenheiro do projeto Conga, em entrevista)". Revela-se na explicação por parte do representante de Yanacocha o argumento de que com a intervenção haveria melhor dinamismo na economia. É assim que as empresas de mineração e o Estado colaboraram para que vários projetos de desenvolvimento de grande escala se fizessem presentes no Peru como dádivas para serem aproveitadas de forma planejada. Neste artigo examinamos um processo recente de lutas e manifestações contra iniciativas de mineração em Cajamarca e proximidades, no Peru. Está em análise como se formula a defesa da vida em associação à defesa das águas, eixo central nos conflitos socioambientais na região. Ademais, para tal argumentação será preciso recorrer a certos aspectos que auxiliam na interpretação, tais como formas de aprendizado coletivo para as lutas, experiência social e memória. O tema do desenvolvimento será pincelado ao longo do texto antes de uma seção específica sobre o assunto, uma vez que também está no epicentro desta trama sobre mineração e dinamismo econômico.

A pesquisa etnográfica concluída por uma das autoras deste texto foi conduzida entre os anos de 2013 e 2014 completando nove meses de investigação e foi realizada especialmente nos municípios de Cajamarca, Celendín e no centro poblado ${ }^{6}$ El Tambo, que também se localiza na região de Cajamarca, lugares onde um grupo expressivo da população manifestou oposição à exploração minerária. Como parte dos aspectos ético-metodológicos, é importante ressaltar isto: uma das autoras tem realizado pesquisa na região de Cajamarca há alguns anos (inclusive para conclusão de sua tese de doutorado). Os autores dialogam e escrevem juntos pelo menos desde 2007 e o segundo autor se dedica a um tema transversal a este artigo - a relação entre

6|Compreende um ou mais assentamento reconhecido legalmente. É sede das autoridades do governo, locais e comunais. O centro poblado El Tambo conta com 26 caseríos, que expressa um assentamento reconhecido legalmente. Não dispõe de títulos coletivos de terra, mas é reconhecido como uma unidade organizativa para efeitos dos serviços governamentais. biopolítica e desenvolvimento.

O contexto desses anos era de conflito em torno do projeto de mineração Conga, uma proposta grandiosa de exploração de ouro e cobre a céu aberto que seria 
instalada nas partes altas da região Cajamarca. Similar ao caso Quilish, antes mencionado, Conga faz parte do planejamento de expansão da polêmica mina de ouro já em atividade nos arredores de Cajamarca desde 1992 de nome Yanacocha cuja empresa responsável pelo empreendimento é a maior da América Latina neste setor?

Em 2010, os meios de comunicação destacaram que conhecidas lagoas da região de Cajamarca (denominadas El Perol, Chica, Mala e Azul) seriam diretamente afetadas pela instalação da infraestrutura do projeto de mineração. A água, argumentamos, é fundamental em diferentes acepções para os grupos da região. Contrariamente à multiplicidade da água e da vida presentes na política, na memória e nas experiências dos moradores dessas regiões, a empresa mineradora a apresenta como um recurso passível de exploração por meio de um procedimento técnico que consiste na construção de reservatórios para o armazenamento das águas das chuvas. Foi justamente este redesenho artificial que provocou a exaltação de cajamarquinos, sendo que alguns já tinham participado das manifestações pela libertação do cerro Quilish e conviviam diariamente com os efeitos de Yanacocha sobre suas vidas. $\mathrm{O}$ argumento da empresa é ainda reforçado como melhoria tecnológica e garantia de maior captação de água em comparação com a quantidade abrigada pelas lagoas (Knight Piesold Consultores, 2010). Vários destes aspectos serão discutidos neste texto e procuramos dar ênfase à etnografia, estabelecendo conexões teóricas a partir dos eventos e processos sociais.

\section{EXPERIÊNCIA E APRENDIZADO: ÁGUA, VITALIDADE EAÇÃO DAS RONDAS CAMPESINAS}

Nora nasceu e reside na cidade de Cajamarca, tem 44 anos, é professora de escola e costuma sair às ruas quando há manifestação contra a mineradora Yanacocha. "Eu não tenho grupo fixo, se vejo um grupo de mulheres protestando, fico ao lado e grito junto". Como outros depoimentos durante a pesquisa etnográfica, é usual e corriqueiro este processo de resistência à mina, pois o suprimento e a qualidade da água são recorrentemente afetados. $\mathrm{Na}$ época desta conversa, em abril de 2014 , as pessoas da cidade de Cajamarca tinham poucas horas de água por dia e essa água, que chegava pela tubulação, tinha aparência duvidosa de acordo com vários relatos.

Nora lembra ter brincado desde jovem, com a sua família, no rio Maschcon, importante na região. Neste diálogo, ela faz as suas reflexões sobre o rio, que se junta com o Rio Grande, outro significativo para a população local.

\footnotetext{
Desde que veio a mina, não tem vida. Entramos (no rio) e a pele arde e dói. O pequeno [sobrinho] não pode ir ao rio. O [sobrinho] que tem 19 anos até os cinco anos desfrutou do rio. O sobrinho mais novo nasceu já com o rio morto. Ele não acredita em mim. Quem de nós vivemos e desfrutamos, saíamos a lavar, era um rio com vida. [...] Aqui hoje temos acequia
}

7 Consórcio integrado pelas empresas Newmont Mining Corporation, norte-americana, que detém $51,35 \%$ das ações, a peruana Buenaventura, com $43,65 \%$, e a Corporação Financeira Internacional, organismo dependente do Banco Mundial, com 5\%. 


\begin{abstract}
[canal] que vem de três moinhos, tínhamos plantas, flores, havia ciprestes; chegou a mina e morrem os ciprestes, como se houvessem se queimado. A água desce amarela e destrói tudo: animais, plantas e nossos filhos. Faz muitos anos que estão morrendo com câncer, como minha vizinha. Minha irmã de 46 [anos] e minha vizinha de 47. Nunca havíamos escutado que alguém morresse de câncer tão jovem. Morreram os vizinhos. Um cajamarquino morria antes de gripe, peritonite, mas nunca com câncer. Agora todos morrem com câncer. Sem sermos cientistas, vemos a destruição, mas nos dizem que temos que comprovar cientificamente. Somente um cego não vê isto. (Nora, professora e ativista da cidade de Cajamarca, em entrevista. Todas as entrevistas foram transcritas e traduzidas para língua portuguesa).
\end{abstract}

De acordo com seu depoimento, seus sobrinhos mais velhos têm memória de terem brincado nos cursos d'água. Contudo, ela lamenta muito pelo seu sobrinho caçula, que não pode ter a experiência.

Ao longo desta conversa, Nora insistia que quem luta mesmo (contra Yanacocha) é porque havia brincado no rio e desfrutado das águas, de maneira geral. Este testemunho acaba por ser similar ao que Cruikshank (2005) estudou sobre como as paisagens ancoram memórias e reflexões. O que chama a atenção na fala de Nora é justamente a ruptura da sua relação com o rio, onde ela brincava com a sua família, uma relação que não pode ser reproduzida com e entre os mais jovens. Contar a seu sobrinho menor a respeito desta experiência é possível, mas algo que ele não consegue partilhar com a mesma intensidade. Para Nora, aquela relação vivida com o rio, a sua memória, é o que a leva a protestar nas ruas sem naturalizar as constantes transformações que estão ocorrendo em Cajamarca.

Porém, não se trata de afirmar que a experiência morreu, talvez justamente o impressionante é como ela fala da morte. Hoje, como enfatiza Nora, as experiências que os cajamarquinos sentem na cidade de Cajamarca são as consecutivas mortes em seus bairros. Nora comentava que os vizinhos morrem de câncer, inclusive a sua irmã, que recentemente havia falecido: antes se morria de peritonite, gripe, mas, hoje, todos morrem de câncer. Aquele não foi um comentário exclusivo porque muitas pessoas falaram de fenômenos semelhantes. Antes, as pessoas eram belamente gordas e, hoje, estão chupadas, como dizem, com corpos moles, efeito que, segundo entendem, somente podia ser oriundo da água contaminada.

Temos um jogo, portanto, bastante diferente quanto à atribuição de culpa. Enquanto a culpa imputada por líderes do Estado e empresários pela suspensão do projeto de mineração Conga é atribuída aos camponeses e aos movimentos sociais - e se torna, então, culpa pela falta do desenvolvimento ${ }^{8}$-, estes atores culpam as empresas e a água contaminada - resultado da mineração em diferentes locais e, assim, efeito do desenvolvimento - pelas doenças. De um lado, o foco está no dinamismo do setor econômico, de outro a própria vida, assunto que trataremos mais adiante neste texto.
$8 \mid$ Apesar da polissemia a ser assinalada ao longo do texto, partimos da ideia de que desenvolvimento pode entendido a partir de uma referência de Olivier de Sardan (1995) citado por Carneiro (2012: 134): "o conjunto dos processos sociais induzidos por operações voluntaristas de transformação de um meio social, empreendidos por meio de orientação de instituições ou atores exteriores a esse meio, e que se baseiam no transplante de recursos e/ ou técnicas e/ou saberes." 
Vale a pena ressaltar que, com base no que foi escutado em campo, o câncer era uma doença diferente. Esta enfermidade parece ter introduzido outra relação com a morte na região. Um rondero $0^{9}$ na cidade de Celendín relatou uma vez que, antes, os mayores [mais velhos] lutavam contra a morte, agarravam-se à porta, à cama, para que a morte não os levassem; enfrentavam o perecimento até o final. Hoje em dia, também confirmado pelo relato de Nora, o corpo parecia não ter essa resistência de brigar contra a morte, o câncer os pegava antes, enfraquecia-os, logo morriam. Outra rondera, Bianca, havia mencionado o mesmo: os jovens têm "corpos fracos", cansados; "deve ser dessa água", desabafou.

Pela conversa com Nora, entende-se que as pessoas capturavam a vitalidade do rio em experiência comunal naqueles anos antes de 1992-1993. Em diálogo com um dos técnicos da Secretaria de Meio Ambiente do Governo de Cajamarca, este relatou que o rio é uma referência muito importante para as comunidades andinas porque as pessoas se encontram lá para buscar e carregar água, lavar, beber, e novas famílias emergem a partir desses encontros. Hoje, diversamente, capturavam alguma doença, e a opção era ter uma vida na qual o rio não fosse mais parte daquela amálgama de relações. A experiência, em outras palavras, não parece ser um assunto somente social ou cultural tal como as abordagens clássicas em ciências sociais supunham (natureza versus cultura), ela envolve uma relação com o mundo, o ambiente e, aqui, a água adquire uma centralidade impressionante. Assim, a vitalidade das águas possui paralelos com a vitalidade das pessoas. Para Nora, destruir essas experiências com as águas é uma forma de usurpação, porque muda aspectos cotidianos, porém centrais, para a vida, tais como os passeios familiares, as expedições com os seus alunos da escola e, sobretudo, a saúde. As experiências com o rio - brincar, passear e até namorar - tinham sido rompidas desde que chegou a empresa Yanacocha, pois se trata de um rio de cheiro nauseabundo. A nova experiência consiste em receber telefonemas pela notícia de alguma morte ou convite a velórios e enterros. No entanto, Nora luta, procurando reconstruir uma experiência de poder retomar os desenhos dos próprios projetos de vida.

Pode-se indagar de que modo relacionar esta experiência com a história e com o coletivo. Uma possibilidade, já que é frequente relato de muitas pessoas e também mencionada por pesquisadores, está no surgimento das Rondas Campesinas ${ }^{10}$. Nossa intenção nesta parte não é fazer um exame minucioso deste processo, já bem conhecido da literatura sobre formas alternativas de justiça, porém é relevante situar esta experiência para compreensão dos demais aspectos do texto.

O estudo de Gitlitz (2013) disserta sobre a justiça rondera de Cajamarca. Esta não consiste em um conjunto de normas definidas e procedimentos específicos a serem seguidos ponto por ponto, como ocorre em uma investigação e o posterior julgamento convencional. Ao contrário, o objetivo da justiça rondera é a reparação das vítimas e a reintegração do ofensor para que este compreenda o seu erro e não continue lesando a comunidade. Em alguns casos, o ofensor tem que rondar para
9| O termo rondero diz respeito à pessoa que realiza ronda de vigilância comunitária na região, tema brevemente explorado ainda nessa seção do artigo.
10| As rondas campesinas de Cajamarca emergiram como uma resposta comuna e organizada ao abigeato e a outros pequenos furtos (Gitlitz, 2013; Starn, 1991) na década de 1970. O roubo era uma atividade altamente estruturada que envolvia gangues, pessoas de dentro do caserío e até a própria polícia. Assim, em 1976, os campesinos de Cuyumalca um caserío de Chota (região de Cajamarca), organizaram a primeira ronda campesina. 
que sinta o sofrimento daqueles que rondam à noite para proteger as pessoas que 0 ofensor prejudica. De acordo com um rondero, Néctar, alguns ex-ladrões do caserío se tornaram os melhores ronderos. Cumprir tal tarefa é um dever na comunidade, todas as famílias tem que realizar e se a pessoa não pode por ter idade avançada deve colaborar com alimentos para os que fazem esse labor.

No centro poblado El Tambo, por anos, os ronderos, que também são camponeses, compartilham um conhecimento vivido com relação à água. A água é algo muito precioso. Como explicou um deles, se o manancial está vertendo água, as pessoas que residem águas abaixo (terras de menores altitudes) sabem que está chovendo nas jalcas (alturas); se está com pouca água é porque se está em tempo de seca (ausência de chuvas). Ao mesmo tempo, eles têm se tornado conhecedores do sistema de canais d'água. Como ronderos que administram relações e usos dos mananciais dentro da comunidade, eles mudam as regras, desenham e reinventam sanções para evitar que um prejudique o outro pelos "roubos de água". Quando alguém percebe que sua terra precisa de água, a permissão deve ser dada pelo administrador principal, e o usuário deve irrigar até terminar seu lote plantado para que outro tenha acesso ao canal. Se um usuário detém a água por capricho, há sanção, porque é uma falta

11 | Na pesquisa de Caballero (2017) no centro-sul dos Andes peruanos, o roubo de água é analisado pela autora como uma ação egoísta que fere o coletivo da comunidade. grave reter a água e deixar outro sem poder irrigar sua terra. Este tipo de atenção à boa utilização da água é cumprido rigorosamente para que todos possam alimentar suas terras.

No entanto, a posição contrária aos projetos mineradores por parte dos ronderos de El Tambo não foi imediata, mas um processo de contínuo aprendizado para o qual as memórias atuaram. Galindo, professor e também rondero, contou que hoje é contrário ao projeto Conga, e relatou que em um momento ele próprio convidou o Gerente de Relações Comunitárias da empresa Yanacocha para visitar a comunidade com propósito peculiar:

\begin{abstract}
Em princípios de 2006, quando fui Conselheiro do centro poblado, queríamos o desenvolvimento no El Tambo. As prefeituras não apoiavam. Trouxemos o gerente de Relações Comunitárias de Yanacocha para apoiar com infraestrutura: construção da praça de armas, mercado, estradas. Eles vieram e se comprometeram, mas puxaram certas pessoas para a sua conveniência, para apoio pessoal. Vendo isso, percebemos que não queríamos desenvolvimento pela mineração. A mineração somente dá migalhas a algumas poucas pessoas. Principalmente às pessoas que vão trabalhar para eles (Galindo, rondero, professor e Presidente do Frente de Defesa, em entrevista).
\end{abstract}

Galindo continuou falando que:

Em outubro de 2011 ocorreria uma audiência pública para aprovar a licença social. Enviaram um ofício para os professores. Nós tínhamos que ter uma posição. Antes da audiência 
pública organizamos um Comitê de Meio Ambiente. Após a audiência fundamos a Frente de Defesa dos Interesses e Meio Ambiente do centro poblado El Tambo. Na audiência explicaram que o Projeto estava em execução (construção). Fomos no dia 9 de novembro até o Amaro, entre a lagoa Azul e a lagoa o Perol, e vimos uma grande quantidade de maquinário na estrada, e acordamos como Frente de Defesa em dar um ultimato ao projeto de mineração Conga para retirar o seu maquinário. Foi aí que nos demos conta que iriam destruir todas as nossas lagoas em cabeceira de bacia. Conseguimos o Resumo Executivo do Estudo de Impacto Ambiental. Aí vimos que iriam desaparecer as lagoas. Em 24 de novembro começamos com a Paralisação. ĺamos aos caseríos com os documentários sobre Cerro de Pasco para mostrar como iria ficar o centro poblado El Tambo. Conscientizamos tanto às pessoas de Cajamarca como as de outras províncias. E, quando realizamos a Marcha Nacional da Água, outras regiões, como La Libertad e Ancash, nos respaldaram.

Aparentemente, aqui ocorre algo usual em grandes projetos de desenvolvimento. Todos, ou muitos, são favoráveis quando ficam sabendo que haverá um grande investimento em sua região. Normalmente, as pessoas imaginam a quantidade de recursos e a geração de empregos a serem gerados. Inicialmente, as rondas campesinas se colocavam nesta situação, com muitas pessoas apoiando a iniciativa de exploração de minérios mesmo que não conhecessem bem os casos diversos envolvendo mineração no Peru. Porém, pelo depoimento acima, os ronderos tinham que ver os possíveis efeitos pelos seus próprios olhos, mas para aqueles que já sabiam dos problemas comunicar isso para os outros era difícil - um trabalho que não poderia ser somente de convencimento pelo discurso. Tinham que mostrar os vídeos de outras situações de mineração, como o polêmico caso de Cerro de Pasco ${ }^{12}$ para poder demostrar os vários efeitos da mina. A possibilidade de que as rondas atuassem no processo de aprendizado coletivo a respeito dos projetos de mineração era iminente.

Os aprendizados postos em marcha pelas rondas compreendem que o que está em jogo hoje não diz respeito somente a um problema de defender a propriedade de cada um. Esta, sem dúvidas, foi uma das motivações principais do surgimento destas formas de justiça, mas quando o território é cada vez mais alvo de prospecção mineradora, outro tipo de situação entra em jogo. Diante da problemática de Conga, houve certas mudanças que podem ser vistas a partir do que propõe Starn (1991). As Rondas renovam os seus próprios costumes de justiça local e hoje incluem o cuidado às lagoas da região de Conga. Desde 2012, os ronderos de El Tambo têm se autodenominado como Guardiões das Lagoas, estendendo a vigilância do que era antes o seu território, a comunidade, até a região de Conga, onde estão localizadas as emblemáticas lagoas.

Existem famílias no centro poblado que não têm membros com a idade para rondar. Estas pessoas não se autodenominam ronderos, mesmo assim participam das Assembleias, colaboram com alimentos e estão sujeitas às normas das Rondas;

12 Cerro de Pasco é uma das maiores minas a céu aberto da América Latina, localizada na região de Pasco, Peru. $\mathrm{O}$ caso é famoso pelo fato de a mina estar próxima de onde residem pessoas, muitas das quais apresentam graves problemas de saúde. 
eles costumam dizer "nossos ronderos" ou "nossos guardiões". Até alguns cantam em apoio: um conhecido camponês da comunidade, já com idade avançada, canta corriqueiramente na estação de rádio do caserío e sua voz é escutada nas jalcas para animar os Cuardiões na sua importante tarefa de velar a lagoa Mamacocha, uma das possíveis afetadas pela mineração. Reciprocamente, os Guardiões sempre têm que informar o que é observado via inspeção ocular: alguma mudança na paisagem, trailers saindo por perto da lagoa El Perol (em Celendín) e passando pela Mamacocha (em Hualgayoc), presença de policiamento, maquinário, alteração de comportamento dos vizinhos, entre outros. Por outro lado, eles também eram vigiados pelos próprios vizinhos (os que estão a favor do empreendimento) e pela polícia, e, por isso, durante a etnografia se notou tanto cuidado em fornecer permissão para os pesquisadores que querem estudar estes problemas. Os ronderos sempre faziam questão de mencionar: "podem ser infiltrados" [da empresa].

A luta ensina, sentenciou Paredo, outro rondero e interlocutor em campo e que possui conhecimento suficiente do grupo para interpretar o processo no tempo: apesar de sempre ter sido projeto coletivo, completou que "antes as Rondas estavam para cuidar os nossos pertences (de cada um) hoje está para cuidar o que é de todos".

\section{ÁCUA E VIDA: PARA ALÉM DAS PARTES E DO QUE CABERIA A CADA UM}

Aos poucos que se consegue tecer um fio que liga as histórias individuais ao coletivo e aos processos políticos envolvendo a mineração, a vida e as águas. Para Nora, antes apresentada, os problemas relativos à água são mais que meros acidentes de percurso do suposto desenvolvimento, tampouco são particionados como exclusivamente ambiental ou de saúde. A água, podemos assegurar, é um nó fundamental de relacionalidade. Os problemas advindos com a mineração a céu aberto ocasionaram interrupções nas vidas das pessoas, as quais tiveram que forçosamente se separar do rio, compreender a perda da vitalidade do corpo e buscar outras formas de impedir as doenças. Mas estas mesmas interrupções são o que acabaram dando força à luta, como disse Nora uma vez: "tornaram-nos pessoas da luta". Veja-se bem aqui que Nora, sendo professora por profissão, não nega ser cajamarquina e, acrescenta, "lutadora”, tal qual é discutido em Vieira e Maizza (2018) ao apresentar como as mulheres questionam a sua categoria (mulher) em momentos de disputa e se tornam politicamente visíveis e entrelaçadas com os não-humanos.

\footnotetext{
Antes (o rio) era nosso ponto de diversão, a vida era bonita. O popular cinco, quando uma pessoa morre, no quinto dia lavava-se a casa e lavavam-se as roupas do defunto no rio Maschcon. De passeio, os professores nos traziam ao rio Maschcon, e nos diziam: vamos estudar o rio. Agora o rio não tem vida; um [indivíduo] que o tem sentido sabe o que defende, sente uma nostalgia, uma euforia; basta, queremos viver como antes. Agora não se pode,
} 
tudo morto. O cinco da minha irmã lavamos nos Baños del Inca para que ela vá bem. Tem que
seguir a crença, é uma tradição que vem de geração em geração, é como um relax, a água
significa vida, purificação, lavar as roupas dela para que ela parta bem ao além. Água é vida,
é o sustento de vida, da tua alma, das plantas. [...] Uma vizinha trocou o seu terreno por uma
casa de quatro andares na cidade, duas camionetas... imagina, vir do campo. Ela disse: "já
não posso criar meus porcos". A minha mãe dizia, se se queima a tua colheita, volta a arar e
volta a plantar. Agora, nunca mais vai dar. [...] Antes [a terra] dava batata, ocas [um tubérculo
andino], cevada, centeio. (Nora, professora da cidade de Cajamarca e ativista, em entrevista).

Em torno da frase a "Água é vida", Nora sintetiza bem o que sente, articulando religiosidade, pureza, trabalho, relação entre gerações, colheita, saciedade da sede e alimentação. Essas lutas pela vida são uma amostra de que muitos saem daquela categorização - que despolitiza - na qual estão encapsulados: de professor, de camponês, de dona de casa, de mulher, etc., para agir politicamente, recuperar as experiências possíveis, desenhar projetos de vida.

O mesmo vale para os ronderos, dos quais muitos são camponeses, ou para outras pessoas. Essas identidades são sobrepostas e ativadas em determinados momentos, em geral não são excludentes. Este também pode ser um aspecto da extensão das relações, que nunca podem ser supostas pelo pesquisador, como bem mostrou Strathern sobre redes e suas complexidades em texto marcado por diálogo crítico com Bruno Latour (Strathern, 2006). O poder policial, aliás, justamente procura separar e compartimentalizar aquilo que pode ganhar força na articulação e na luta política.

Outro caso bastante emblemático é o de padre Sergio. Foi justamente Nora quem sugeriu para que se entrasse em contato com ele durante a pesquisa de campo. O sacerdote foi ativista quando ocorreu o caso trágico de derramamento de mercúrio em Choropampa, local próximo. Assim, são muitas as pessoas que têm alguma vivência dos problemas políticos e ambientais da região. Após ter participado em vários protestos durante a década de 2000 , Sergio relatou que ele foi separado da cidade de Cajamarca pelas próprias autoridades religiosas justamente por participar das manifestações e, que, segundo seus superiores, ele enquanto padre não tinha a competência para se envolver na política.

Durante o tempo de convivência nos Andes, a partir dos comentários de diversas pessoas, começou a ficar claro que havia um esforço de forças poderosas para a separação entre política e as demais funções, tal como o caso de Nora antes apresentado. O Estado fazia política (provavelmente mais no sentido de políticas, policy), os outros que faziam política eram por favorecer algum partido político do qual obteriam algum benefício, construir política combativa ou se colocar no mercado para receber dinheiro por silêncio. Se seguirmos Rancière (1995), parece que neste caso o Estado realiza policiamento e administra política pública, dividindo e funcionalizando partes da sociedade. Aparece também em Foucault (2004) e em 
Agamben (2007) esta tensão curiosa: o primeiro mostrou como há poucos séculos na Europa ocidental polícia significava muitos tipos de ação do Estado para com a sociedade, inclusive a gestão do bem-estar. A noção de polícia tal qual conhecemos hoje - segurança e ordem pública -é mais recente. Para o segundo, há uma tendência histórica no Ocidente de pensar política como governo e economia das coisas, das almas e dos outros, tema também de reflexão de Foucault no que toca à questão da governamentalização do Estado.

Sergio explicou que, desde 1979, e principalmente no documento da Aparecida do ano de $2007^{13}$, ficou determinado que a questão ambiental era um assunto a ser pensado pela Igreja Católica, e é o que hoje o Papa Francisco enfatiza por meio de sua Alegria do Evangelho, de 2012, e a encíclica Laudato Si, de 2015. O padre seguiu em sua argumentação e enfatizou: "a natureza é a mais oprimida que tem. O pobre é reanimado, mas os danos à natureza são irreversíveis"14. Influenciado pelos escritos dos teólogos e filósofos da Libertação (Boff, Gutierrez, Dussel, entre outros), trabalhou com estes referenciais junto com outros seis clérigos das Dioceses de Cajamarca. Cabe mencionar que, no final dos anos de 1960 e 1970, a Teologia da Libertação pautava que não era suficiente que a Igreja simplesmente tivesse empatia e cuidado pelos pobres. Em vez disso, a Igreja precisava ser um veículo fundamental que pressionasse por mudanças políticas e estruturais a fim de erradicar a pobreza (Boff, 2007). Segundo declarou Sergio, esse é o papel do religioso, enquanto o bispo sob o qual estava vinculada sua paróquia fazia questão de esclarecer que isso não é competência dos padres, discurso típico do movimento interior à Igreja para combater tendências marxistas. No ano de 2006, o atual bispo de Cajamarca, Martinez Lazaro, publicou uma carta no diário El Correo, dirigida à Diocese de Cajamarca, na qual justificava que os sacerdotes estariam proibidos de participar de qualquer ação de cunho político. Para esse argumento, o bispo alude ao discurso de Paulo VI às Nações Unidas, em 1965, o qual expõe que o desenvolvimento é a nova linguagem da paz, e à afirmação paulina de que o conceito evangélico de cristianismo não está em socorrer os pobres para que estes sigam sendo pobres; ao contrário, reside em que estes desprovidos saiam de um estado e passem a um patamar superior.

O que se observa, assim, é que tanto o ordenamento do mundo é dado a partir de categorias, competências, parcelas e papéis que caberia a cada um (tal como examinou Rancière, 1995), e muitos dos atores em campo se percebem transgredindo essas limitações.

Parece haver política neste caso justamente quando se rompem estas funções que são destinadas às pessoas, assim como as identidades se tornam políticas quando elas implodem os espaços de domesticação a elas reservadas. Mesmo assim, desejamos destacar que o desenvolvimento-tema que apareceu de forma recorrente neste texto quando se mencionam ou prometem efeitos positivos da mineração-constitui forma poderosa de linguagem para mitigar conflitos.
13 | "Esta herança muitas vezes se manifesta frágil e indefesa diante dos poderes econômicos e tecnológicos. Por isso, como profetas da vida, queremos insistir que, nas intervenções sobre os recursos naturais, não predominem os interesses de grupos econômicos que arrasam irracionalmente as fontes de vida, em prejuízo de nações inteiras e da própria humanidade". Esta é uma das passagens dedicadas à questão ambiental do Documento de Aparecida, de 2007.

14 O padre Guille, de Celendín fez questão de mostrar durante uma entrevista a Alegria do Evangelho, introduzida pelo Papa Francisco, e que era discutido nas suas reuniões. 


\section{DESENVOLVIMENTO: OS ARGUMENTOS EM TORNO DA TÉCNICA, DA DEMONSTRAÇÃO DO SUCESSO E DA PRODUTIVIDADE}

Que estágio superior seria este e como realiza-lo através da linguagem da paz, tal como aludido antes? Justamente o que supera o subdesenvolvimento e seus atributos constitutivos que o núcleo duro das teorias da modernização apregoa (pobreza, falta de racionalidade orientada a fins por parte dos atores sociais, estagnação econômica, problemas de dinamismo produtivo para uma sociedade de consumo de massa e outros).

Em que pese poderíamos incidir no tema por uma crítica em termos de debate conceitual, será mais frutífero retornar ao problema do desenvolvimento e alguma conexão feita pelos interlocutores em campo. Num dos momentos da conversa com Nora, sequer havia encaminhado a discussão para o tema do desenvolvimento e ela, porém, começou a explicar que o desenvolvimento propagado pela empresa Yanacocha é justamente de fazer com que todos adquiram uma "camionete Hilux". O desenvolvimento, assim, é ligado à aquisição de bens materiais a serem mostrados aos outros, forma também de sedução das empresas mineradoras. Claro, o desenvolvimento, com base em Ferguson (1990) e Escobar (1995), tem efeitos reais e isto que importa examinar, não como os teóricos do desenvolvimento gostariam que este fosse $\mathrm{e}^{15}$. A camionete e a casa na cidade, no caso citado por Nora, são bens considerados externos ao modo de vida camponês, certamente sedutores e signos de poder ou ascensão social. Seus desenhos são realizados por outros, engenheiros e arquitetos. Contrariamente a isto, as pessoas que apresentamos ao longo do texto invocam o seu direito de decidir sobre seus projetos de vida, nos quais o desenho de seu mundo é importante. Walsh (2010) chamou a atenção à grafia da palavra como em "des-envolver", um processo de rompimento das relações das pessoas com o que é seu mundo e, assim, anula-se a autonomia do desenho dos seus projetos de vida (ver também Escobar, 2018; Ryn e Cowan, 1996).

Enquanto continuava a falar, Nora mostrava alguns paralelos, pois se o motor da camionete estragasse não se podia fazer muito; seria necessário o conserto por um terceiro, geralmente um especialista. É diferente com a terra, se a colheita de batata não dá, seguia narrando Nora, pode-se desenhar nela de novo. É um processo de experimentação, mas também de experiência vivida com a terra (e com os canais de irrigação, ou seja, água). Ao falar de desenvolvimento, estava enfatizando a habilidade de desenhar o seu próprio projeto de vida, de não ter uma dependência de terceiros, enfim, de ainda ter autonomia para articular suas relações com as coisas. Mais importante, para ela, é que o desenvolvimento faz uma pessoa se vincular a algo que não é do seu mundo.

Alguns dos relatos coincidem com a literatura crítica a respeito do desenvolvimento, pois enquanto se observa que é um tema político ele pode ser - por isso mesmo - colocado em um terreno fora da política. Trabalhar, consumir, progredir,
15 | Este é um longo debate nas ciências sociais e não será detalhado no texto. A discussão sobre como o desenvolvimento tem sido versus como as pessoas gostariam que fosse gera muitas confusões, tanto nos estudos como nas políticas públicas, o último respondendo em parte o porquê não se abandonou ainda este ideário e se acredita na possibilidade de um dia construir um "bom" desenvolvimento. Sobre o tema, ver Perrot (1991), Rist (1996), Ribeiro (2008), Ziai (2007, 2015), Mosse (2013). 
menos do que se discutir que relações de poder podem envolvê-lo está-se às voltas com uma espécie de conquista (individual ou coletiva). Ferguson (2005) mostrou que a partir de meados do séc. XX desenvolvimento tomou o lugar que em outros tempos coube aos vocábulos evolução e progresso, agora numa nova arquitetura de relações internacionais: desenvolvimento é algo a ser estimulado e todos os povos, com tempo e recursos, poderiam superar a estagnação e o subdesenvolvimento. Mas é em uma monografia (Ferguson, 1990) que o autor indicou como os programas de desenvolvimento podem ser despolitizantes, uma vez que substituem o debate político pelo saber técnico (e pela administração de políticas ou gestão de grupos sociais). Assim, participar de protestos sociais não é um assunto da competência dos religiosos, e muito menos o é entorpecer a oportunidade destes povos de sair da pobreza - argumento dos grupos pró-mineração. Mas esta saída parece sempre guiada pelo Estado, por empresas ou pela caridade e então pobreza se torna assunto de intervenção, gerenciamento e políticas focadas, não um problema político relativo à desigualdade estrutural.

Sugeria Sergio que a região de Cajamarca estava dividida entre os a favor e os contra mineração e desenvolvimento era um termo do qual ele procurava também libertação. Criticava a noção de que o desenvolvimento fosse único e dirigido por um progresso linear. Na vida real, se o desenvolvimento deveria existir, ele dizia, teria que ser "do ponto de vista da pessoa". Para alguns, é para ter uma camionete; para outros, é para poder viver da sua agricultura, e existiriam outras concepções. Então, essa divisão parecia não aceitar a multiplicidade de sentidos (e opções de vida) que o termo poderia assumir. De um lado, a mineração e, de outro, todos aqueles que não estavam a favor da atividade mineradora eram rotulados também de "os contra o desenvolvimento". O material etnográfico permite afirmar que para os opositores dos projetos de mineração suas alternativas jamais poderiam ser entendidas como formas legítimas de construir projetos individuais ou coletivos de vida.

Ainda assim, cabe destacar um fato relevante conexo a estas opções. De acordo com o padre Sergio, muitos dos clérigos em Cajamarca tinham optado por apoiara mina porque recebiam dinheiro para suas obras sociais. Durante os protestos contra o projeto Conga, somente alguns padres ajudavam a resistência. A oferta chegou a Sergio e, conforme relatou, foi procurado em sua paróquia; estava em jogo a questão de se receberia dádivas das companhias mineradoras. Mas ele se negou a receber esta oferta, teve a coragem de negar o segundo momento da dádiva bem descrito por Mauss (1925), o receber, porque esse dinheiro viria com um compromisso. Sabe-se desde Mauss como dádiva e poder estão entrelaçados e os padres que escolheram receber a dádiva das mineradoras agora precisam falar bem da mineração. Então, se você ganha das empresas, depois "te lo sacan en la cara" (cobram o favor), disse Sergio. O tempo entre o receber e a contraprestação pode se manter, mas a dívida é evidente e com dificuldade pode se escapar dela. 


\section{AS TÉCNICAS PARA IMUNIZAR}

Telmo, já mencionado na introdução deste artigo, é um engenheiro que trabalhou no projeto de mineração Conga. Conversar com ele permitiu o entendimento acerca do modo como parte do corpo técnico dos projetos de mineração ou empresas consultoras compreende os problemas da região. O engenheiro alegou que é a técnica que permite aproveitar os recursos naturais. Para ele, se o camponês conseguisse entender que a técnica está para aproveitar os recursos de uma melhor forma, estaria a favor da mineração porque esta atua como alavancagem da agricultura: "Quem é o ganadero, os que estão acima? Isso é uma agricultura de subsistência. Todos têm as suas parcelas. Colhem somente para comer". Para Telmo, aqueles que conseguiram ver com melhores olhos a mina estão também apostando em algo diferente e sobressaem. Levam os camponeses ao sul do Peru para ver como é ser pecuarista de verdade e estes ficam surpreendidos. Aqui estamos no terreno do convencimento pela produtividade e pela promessa do aumento de ingressos monetários.

Com relação ao tema de água, continua sendo a técnica a que ajuda que Cajamarca tenha mais água. Telmo explica que os reservatórios ampliam a capacidade das lagoas.

Temos feito um reservatório grande, é algo adicional ao que era antes. Às pessoas que estão longe não lhes chega o benefício e por aí vai o problema. Nesse caso os que já são empresários mudaram a sua visão de perspectiva de desenvolvimento. Eles estão indo a outros lados com as suas empresas. Mas como técnico, com todos os estudos que tenho a mão, tenho visto que o caso das lagoas difere do que as pessoas pensam. Por exemplo, as conexões hídricas das lagoas com o manancial. Primeiro temos que conhecer o ciclo hidrológico: nuvens e ventos condensam-se, há chuva, formam rios, arroios, lagoas, a água se infiltra no solo e essa água forma mananciais. Muitas pessoas diziam em Combayo que temos 500 mananciais que vem de cima (das lagoas de Conga), mas não vem das lagoas, é água infiltrada. No caso de Conga, a geologia do solo não permite que a água se infiltre. Por isso as lagoas são impermeáveis. Não podemos dizer que exista conexão em 100\%. Não podemos dizer que as lagoas alimentam as partes baixas. Como técnico falo com estudos técnicos. Eu tenho explicado o ciclo da água por muito tempo às pessoas e não acreditam. Nós temos falado desde a posição técnica e é bem difícil. Vamos com uma linguagem amistosa para fazer outro acreditar e para que este nos diga Ok. (Telmo, engenheiro do projeto Conga, em entrevista).

Todos os argumentos são dados em razão da capacidade da engenharia responder bem - com desenhos científicos - problemas colocados pelo ambiente ou pela ação humana. Em partes anteriores do texto, mostramos que há uma forte aderência dos atores locais das comunidades às explicações das histórias orais e às experiências cotidianas com o mundo. As conexões hídricas no território são amplamente 
conhecidas e verbalizadas pelos camponeses, que constroem canais de irrigação e os administram coletivamente. Os problemas vividos, tanto a falta d'água como a contaminação (as doenças e mortes), não encontram outra explicação que não oriunda das iniciativas mineradoras, pois coincidem no tempo. Quaisquer alterações nos canais, e isto foi verbalizado por muitos, são sentidas nas terras abaixo e constituem sinal de que algo que ocorre em alguma parte afeta o fluxo das águas.

No entanto, Telmo é enfático em destituir tais explicações por meio da ciência geológica com seu desenho técnico - inclusive contestando o tão repetido depoimento de moradores de que as lagunas alimentam as partes baixas. Além disto, em seu modo de ver, falar da técnica é algo difícil, uma vez que os outros não compreendem. Assim, tanto a produtividade como o saber especializado são adventos de técnicas avançadas, e o desenvolvimento, portanto, também. Tudo o que nos foi contado por Sergio e por Nora, que remetem o desenvolvimento a um assunto que se permitiria pluralidade de concepção e entendimento do mundo, é aqui reduzido a uma versão de verdade que, como Blaser (2010) mostrou sobre o Ocidente e seu modo de pensar a relação entre realidade e conhecimento, procura englobar as demais sugerindo que estas são versões incompletas, imperfeitas e pouco eficientes frente à ciência. Mas outro dos interlocutores em campo nos apontou uma situação diferente propícia para tal questão em jogo, particularmente quanto aos conhecimentos e o lugar e ao modo como desafia o establishment.

Após o congresso organizado pela Frente de Defesa do Tambo em agosto de 2014, uma das autoras deste texto participou de uma noite de vigília em Celendín e visitou o professor Chavito, que era responsável pelo programa de rádio na cidade. Ele havia trabalhado junto com um ambientalista da região, o senhor Nero, com quem visitava as cataratas Cornélio, queda d'água conhecida na região. Na conversa, o professor narrou uma história em um dos encontros Jueves de diálogo que chamou nossa atenção. Relatou que uma vez apareceu uma engenheira que trabalhava no estado do Texas, nos Estados Unidos, para explicar sobre os efeitos do transvase ao público convidado. A situação, como de costume, relacionava-se a tentar tornar o trabalho das empresas mineradoras mais fácil e aceito na região. A palavra transvase se refere ao translado das águas, no caso de quatro lagoas que iriam desaparecer em razão da construção das cavas e das unidades de desmonte e relaves para os reservatórios construídos. De acordo com as informações dos professores e ronderos, esta palavra estava circulando na cidade de Celendín e nos caseríos próximos à área de operações. O seu significado, entretanto, não estava claro entre a população, provocando confusões.

Segundo o relato do professor, a engenheira realizou uma apresentação argumentando que a paisagem da jalca da província Celendín continuaria sendo igual após o transvase das águas das lagoas aos reservatórios. Após a apresentação, o professor, desconfiado, levantou a mão e perguntou: "Desculpe, você conhece a região?", e ela respondeu que não era necessário conhecer, porque para isso existia a virtualidade. Então, ele questionou: "não é assim como você fala". Imediatamente, os engenheiros 
peruanos tomaram a palavra e disseram ao professor: "você vai ter o seu Cornélio". A frase de apaziguamento indicava que nada mudaria no que apreciava o professor, pois Cornélio é o nome de uma catarata muito admirada pelas pessoas de Celendín. As suas águas pertencem ao rio Jadibamba e este nasce da lagoa Azul, justamente uma das lagoas que seriam deslocadas para a instalação de um depósito de dejetos de mineração. Os engenheiros continuaram: "Se seca a lagoa Azul, colocaremos uma bomba d'água que funcione por 24 horas e assim você vai ter o seu Cornélio". O professor respondeu: "cínicos, por esse cinismo é que nunca acreditei em vocês."

Para a engenheira do Texas, a análise e confirmação de que aquilo realmente vai ocorrer pode ser realizada sem estar presente no local, ou seja, em total isolamento da experiência daquele mundo vivido pelo entrevistado, quiçá imunizada contra influências locais. É relevante esta discussão sobre o transvase porque se abre um novo espaço de comunicação (Bhabha, 1990), onde emerge uma controvérsia capaz de abalar a segurança do domínio e o "colonizado" realiza uma imediata contestação: vocês são cínicos, sequer conhecem a região. A virtualidade mencionada pela engenheira texana, típica do pensamento científico moderno e universalista, não é uma metodologia legítima para os professores locais e camponeses que estão contra o projeto, mas sim a convivência com as águas no dia a dia. Para isto, cabe recorrer à noção de "terceiro espaço" de Bhabha (1990), que é descrito por Carvalho (2001) como a possibilidade que o subalterno tem de devolver o caráter inconsistente e frágil daquela ordem que se apresenta como legítima e inquestionável. O trabalho de Mantovanelli (2016) também sugere estar em questão esta disputa, pois na construção de Belo Monte, no norte do Brasil, sua etnografia acentua como os Xikrin não eram ouvidos nos seus próprios termos e não aceitavam que o saber tecno-científico, bem apresentado em gráficos e em números, suplantasse aquilo que era conhecimento aprofundado do ambiente: "Os índios [q]ueriam que os engenheiros ouvissem seus conhecimentos para aprenderem sobre o rio Bacajá e sobre a relação desse rio com o rio Xingu." (Mantovanelli, 2016: 170).

A experiência em Cajamarca acabou por enfatizar vários aspectos. Um primeiro diz respeito ao apelo da técnica em relação ao debate político, como antes foi sublinhado a partir do conhecido estudo de James Ferguson e a máquina anti-política. Um segundo condiz com o primeiro ao se observar que o desenvolvimento funciona como palavra mágica que pode, supõem alguns, estar acima da contestação política, pois parece ser difícil se contrapor a ele - soa como ser contra coisas boas. O problema disso é quando a dádiva das mineradoras se torna dívida que ofusca ou destrói a dádiva da/dívida com a comunidade. Em que sentido? Particularmente, quando Telmo, antes mencionado, mostrava os adventos das técnicas para o desenvolvimento estava indicando que no seu entender o funcionamento da ciência e da técnica moderna escapa dos controles comunitários que, segundo esboça, emperram a adesão a instituições universais da modernidade. Interagir com as companhias que são outsiders pode caminhar na direção de romper tais relações na comunidade, e então 
desenvolver alude ainda mais às intenções da palavra: des-envolver, isto é, retirar as comunidades de um envolvimento em si mesmas.

Um brevíssimo sobrevoo da obra Communitas de Roberto Esposito (1998) sobre o que significa a comunidade no mundo ocidental pode ser instrutivo. Tendo origens em radicais linguísticos que possuem sentidos de dádiva ao comum e pertencimento, para nós o que as companhias mineradoras fazem é destituir o difícil laço que as comunidades querem manter num mundo individualista. Enquanto tal, não o fazem sem que novas dívidas sejam postas em marcha, agora com a lealdade às empresas. Em Esposito, toda a discussão em torno do significado de comunidade no Ocidente é um testemunho da perda deste caráter de encargo que ela exercia sobre os seus membros. O sujeito nascia em uma comunidade e portanto já estava desde seu aparecimento no mundo devendo àquela que lhe era anterior, Ihe fornecia identidade $e$ abrigo. Communitas é um conjunto de pessoas ligadas por um débito ao seu mundo comum. O mundo capitalista e liberal aos poucos destrói este laço comunitário em favor de uma imunidade, elemento que para o autor vem a se tornar a marca da modernidade, a proteção negativa da vida. $\mathrm{O}$ indivíduo é protegido contra o excesso de repressão e de dívidas que a comunidade lhe impõe, assim a vida individual se torna protegida (é a própria biopolítica), mas sob pena de estar disciplinada, controlada por aparatos burocráticos, normalizada (Esposito, 2002).

Um terceiro problema reside no que pode ou não ser associada à fragilidade democrática. No uso policial por parte do Estado contra a contestação à mineração há tanto um apelo discursivo (desenvolvimento = mineração) como violência física de abafamento das manifestações. Esta forma de não deixar em aberto o espaço democrático funciona contra o ato político (the political) de fato, como Rancière entende - para optar por forçar o consenso, daí que se usam os efeitos do desenvolvimento como autoevidentes. Ferguson havia mostrado que uma das mais instigantes maneiras de incorporar a obra de Foucault aos estudos do desenvolvimento é mostrar o que o desenvolvimento faz, o que ele produz (e não o que ele deixa de fazer, como as perspectivas anteriores enfatizavam). Seus efeitos aqui analisados, dentre vários, estão na propagação da ideia de criminalidade ao redor de um projeto de mineração, ou seja, que a crítica e a política se tornam distúrbio da paz e da ordem passível de policiamento, judicialização e para a qual o Estado se vê no direito de intervir.

\section{CONSIDERAÇÕES FINAIS}

Em 2012, com violentos acontecimentos em Cajamarca, a ativista Silva Santisteban (2013) divulga um texto que se tornou em si próprio gerador de mais conflitos. Intitulado Porqué son perros, a autora publicou depois da detenção de um líder ambientalista durante um período em que o governo peruano decretou estado de emergência em Cajamarca, um momento de brutalidade e suspensão parcial de normas vigentes. A autora sublinha a fala 
de uma jovem que pergunta a um policial: "Por que nos tratam assim?". Este responde: "porque vocês são uns perros (...)" (Silva Santisteban, 2013: 451). A culpa sempre está do lado dos que alteram a ordem das coisas (os perros, ou seja, cachorros) e também, aqui vemos claramente, o caminho do progresso. Por causa destas pessoas houve banho de sangue, interrupção nos processos de desenvolvimento, bagunça e problemas de todo tipo. À voz que politiza os acontecimentos se impõe outra que despolitiza.

O mais engrandecedor, no entanto, de acordo com o que foi vivido junto aos interlocutores em campo, principalmente com as mulheres, é que muitas se sentiriam realmente culpadas se deixassem de lutar. A tentativa de governamentalizar existe, não significa que ela tenha sucesso. As mulheres falavam: "os meus filhos me vão questionar: por que não lutou pela água, que aguita vou tomar?". Esta frase aparece na canção de uma das mulheres atuantes, Bianca, que também faz parte do grupo das rondas. É uma luta que dá sentido à vida.

As experiências coletivas, as memórias e o aprendizado que vai sendo adquirido ao longo do tempo tornam as pessoas propensas a enfrentar estes desafios. As rondas camponesas e o sucesso de uma comunidade organizada com formas alternativas de justiça foram e têm sido cruciais para dar sentido ao que ocorre hoje.

A água, por tudo o que foi descrito neste artigo, écentral para os conflitos, ponto também que é matriz das experiências narradas em histórias orais, assim como aponta para um mundo que existiu, que era bonito e cheio de vida, na qual a vitalidade das águas e das pessoas encontravam convergências. Assim, o material etnográfico permitiu concluir que a luta contra a mineração não decorre apenas devido ao problema de falta ou perda de qualidade da água, mas também porque a água conecta-se com a vida e com os modos de existências dos grupos locais. Se a luta existe hoje é porque este mundo não quer ficar no passado e o futuro é sonhado a partir também do que a água pode representar para as comunidades, assim como para o futuro de todos nós. A água indica a força do coletivo e as extensões que as pessoas fazem para expandir cada vez mais sua potência e suas associações mostram o quanto entender as diferentes relacionalidades configura o mundo tal qual ele é para os diferentes coletivos.

Esta relacionalidade também parece estar no alvo das corporações e entes do Estado quando procuram separar, ordenar e compartimentar o mundo, atribuindo lugares e funções, normatizando as relações, disciplinando comportamentos, criando grandes divisões e funcionalizando o social em relação à economia. Mas o que se testemunhou em Cajamarca é o esforço de pessoas em destruir o espaço e o papel destinado, constituindo saídas às limitações e criativamente organizando modos próprios de pensar projetos coletivos e formas de resistência à opulência das empresas e das forças de autoridade do Estado. As identidades são ativamente tornadas complexas e pode-se dizer que a configuração dos espaços de conflito tem relação fundamental em como articulá-las. 
Se a mineração e a maneira como ela é igualada ao desenvolvimento também age de forma coativa, aqui estamos em um espaço ainda mais delicado, pois se utilizam artifícios de ciência e tecnologia para o bem-estar de todos, discursos esperançosos e com roupagens inclusivas, recuperando alguns dos mais nefastos ingredientes do velho evolucionismo. Não apenas como Ferguson (1990) bem mostrou há a despolitização, mas, no caso de Cajamarca, junto a este problema aparece a criminalização dos que estão contra o desenvolvimento. Falar ou fazer algo contra o desenvolvimento parece ser um ato contra o país. A dádiva e a dívida com a comunidade se vê frente às investidas das grandes empresas em substitui-las pelas dádivas e dívidas com a mineração. Sonha-se que o desenvolvimento seja promoção do bem-estar e da vida, porém, inversamente, as referências frequentes a doenças e mortes apontam para o contrário e o que se escutam são vozes de dor e extenuação.

Ouro, cobre, zinco, ferro... em suma, mineração; não é vida, é signo da morte, dizem muitos cajamarquinos. Lutar, neste contexto, é lutar pela vida, assim como água também é vida e produz vida. Estamos em face de projetos que tornam a política da vida não a biopolítica tal qual Foucault bem examinou que constituiu o mundo em que vivemos. Ao contrário, numa pista interessante, Esposito (2007) propôs outra política de vida que não leve como sempre a uma necropolítica, mas uma que seja, na esteira de como querem muitos cajamarquinos, afirmativa e construtiva.

Adriana Paola Paredes Peñafiel é professora Adjunta da Universidade Federal do Rio Grande - FURG (campus São Lourenço do Sul). Tem experiência em pesquisas sobre conflitos em torno da mineração, agricultura familiar e campesinato andino.

Guilherme Francisco Waterloo Radomsky é professor Associado da Universidade Federal do Rio Crande do Sul (UFRCS) e docente do Programa de Pós-graduação em Sociologia (PPCS). Realiza pesquisas sobre Antropologia e Sociologia do desenvolvimento.

\section{CONTRIBUIÇÃO DE AUTORIA:}

Adriana Paola Paredes Peñafiel contribuiu para o desenho da pesquisa, obtenção de dados de campo, concepção do artigo, discussão teórica, análise, escrita e revisão final do texto.

Guilherme Francisco Waterloo Radomsky contribuiu para concepção do artigo, discussão teórica, análise, escrita e revisão final do texto.

FINANCIAMENTO: Coordenação de Aperfeiçoamento de Pessoal de Nível Superior (CAPES) e Fundação de Amparo à Pesquisa do Estado do Rio Grande do Sul (FAPERCS). 


\section{REFERENCIAS BIBLIOGRÁFICAS}

ACAMBEN, Giorgio. [2007] 2011. O reino e a

glória: uma genealogia teológica da economia

e do governo. São Paulo, Boitempo.

BHABHA, Homi. [1990] 2005. O local da cultura. Belo Horizonte, Ed. UFMG.

BLASER, Mario. [2010] 2013. Un relato sobre la globalización desde El Chaco.

Popayán, Universidad del Cauca.

BOFF, Leonardo. 2007. "Teologia da libertação: viva e atuante". Le Monde Diplomatique Bresil, 11 Set. Disponível em http://www.diplomatique.org.br/artigo. php?id=26. Acesso em 22 maio de 2016.

CABALLERO, Indira Viana. 2017. "Forças absorvidas, forças liberadas: aproximações entre festa e trabalho coletivo em um pueblo do centro-sul dos Andes peruanos". Revista Latinoamericana de Antropología del Trabajo, 1 (1): 1-21.

CARNEIRO, Marcelo. 2012. "Práticas, discursos e arenas: notas sobre a socioantropologia do desenvolvimento". Sociologia \& Antropologia, Rio de Janeiro, 2 (4): 129-158. http://dx.doi. org/10.1590/2238-38752012v247

CARVALHO, José Jorge. 2001. "O olhar etnográfico e a voz subalterna”. Horizontes Antropológicos, 7 (15): 107-147. https://doi. org/10.1590/S0104-71832001000100005

CRUIKSHANK, Julie. 2005. Do glaciers listen? Local knowledge, colonial encounters and social imagination. Vancouver, University of British Columbia Press.

ESCOBAR, Arturo. [1995] 2007. La invención del tercer mundo: construcción y deconstrucción del desarrollo. Caracas, El perro y la rana.

ESCOBAR, Arturo. 2018. Designs for the Pluriverse: Radical Interdependence,
Autonomy, and the Making of Worlds.

Durham, Duke University Press.

ESPOSITO, Roberto. [1998] 2003

Communitas: origen y destino de la comunidad. Buenos Aires, Amorrortu Editores.

ESPOSITO, Roberto. [2007] 2012. Third person: politics of life and philosophy of the impersonal. Cambridge; Malden, Polity Press.

FERCUSON, James. 1990. The anti-politics machine: "development", depoliticization, and bureaucratic power in Lesotho. Cambridge; New York, Cambridge University Press.

FERGUSON, James. 2005. "Anthropology and its Evil Twin: "Development" in the Constitution of a Discipline". In: EDELMAN, Marc e HAUGERUD, Angelique (eds.). The Anthropology of Development and Clobalization: from Classical Political Economy to Contemporary Neoliberalism. Malden, Blackwell, pp. 140-153.

FOUCAULT, Michel. [2004] 2008. Segurança, território, população. Curso no Collège de France (1977-1978). São Paulo, Martins Fontes.

GITLITZ, John. 2013. Administrando justicia al margen del estado. Las Rondas Campesinas de Cajamarca. Lima, IEP.

KNIGHT PIESOLD CONSULTORES. 2010. Minera Yanacocha S.R.L. Proyecto Conga: estudio de impacto ambiental. Resumen Ejecutivo. Lima, Knight Piesold.

LI, Fabiana. 2015. Unearthing conflict: corporate mining, activism, and expertise in Peru. Durham, Duke University Press.

LI, Fabiana. 2016. "In defense of water: modern mining, grassroots movements, and corporate strategies in Peru". Journal of Latin American \& Caribbean Anthropology, 21 (1): 109-129. https://doi.org/10.1111/jlca.12198 
MANTOVANELLI, Thais. 2016. "Os Xikrin da Terra Indígena Trincheira-Bacajá e os Estudos Complementares do Rio Bacajá: reflexões sobre a elaboração de um laudo de impacto ambiental.". Horizontes Antropológicos, 22 (46): 159-188. https://doi. org/10.1590/S0104-71832016000200006

MAUSS, Marcel. [1925] 2003. "Ensaio sobre a dádiva: forma e razão da troca nas sociedades arcaicas". In: MAUSS, Marcel. Sociologia e antropologia. São Paulo, Cosac \& Naify, pp. 185-314.

MOSSE, David. 2013. "The Anthropology of international development”. Annual Review of Anthropology, 42: 227-246.https://doi. org/10.1146/annurev-anthro-092412-155553

OLIVIER DE SARDAN, Jean-Pierre. 1995.

Anthropologie et developpment: essai en socio-anthropologie du changement social. Paris, APAD/Karthala.

PERROT, Dominique. [1991] 2008. "Quem impede o desenvolvimento "circular"? (Desenvolvimento e povos autóctones: paradoxos e alternativas)". Cadernos de campo, São Paulo, 17 (17): 219-232. https://doi. org/10.11606/issn.2316-9133.v17i17p219-232

RANCIÈRE, Jacques. [1995] 1996. O desentendimento: política e filosofia. São Paulo, Editora 34.

RIBEIRO, Gustavo Lins. 2008. "Poder, redes e ideologia no campo do desenvolvimento". Novos Estudos Cebrap, São Paulo, 80: 109-125. http://dx.doi. org/10.1590/S0101-33002008000100008

RIST, Gilbert. 2008. The history of development: from western origins to global faith. $3^{\text {rd }}$ ed. London, Zed books.

RYN, Sim van der and COWAN, Stuart. 1996. Ecological design. Washington, Island Press.
SILVA SANTISTEBAN, Rocío. 2013. "Porque son perros. Protestas, discursos autoritarios e industrias extractivas: el caso Conga". In: HOETMER, Raphael; CASTRO, Miguel; DAZA, Mar; ECHAVE, José de e RUIZ, Clara. (ed.). Minería y movimientos sociales en el Perú: instrumentos y propuestas para la defensa de la vida, el agua y los territorios. Lima, Programa democracia y transformación global, CooperAcción, Acsur, Entrepueblos, pp.435-456.

STARN, Orin. 1991. "Reflexiones sobre las Rondas Campesinas. Protesta rural y nuevos movimientos sociales". Revista Quehacer, Lima, v. 74: 60-68, (Documento de Trabajo, 45. Serie Talleres IEP, 2).

STRATHERN, Marilyn. 2006. "Cutting the network". In: MOORE, Henrietta; SANDERS, Todd (ed.). Anthropology in theory: issues in epistemology. Oxford, Blackwell Publishing, pp. 480-491.

VIEIRA, Suzane de Alencar e MAIZZA, Fabiana. 2018. "Ecologia e Feminismo: criações políticas de mulheres indígenas, quilombolas e camponesas". Campos, 19: 9-16.

WALSH, Catherine. 2010. "Development as Buen Vivir: Institutional arrangements and (de)colonial entanglements". Development, 53 (1): 15-21. https://doi.org/10.1057/dev.2009.93.

ZIAI, Aram. 2007. "The ambivalence of post-development: between reactionary populism and radical democracy". In: ZIAI, Aram (ed.). Exploring post-development: theory and practice, problems and perspectives. London, Routledge, pp. 111-128.

ZIAI, Aram. 2015. "Post-development: premature burials and haunting ghosts". Development and change, 46 (4): 833-854. https://doi.org/10.1111/dech.12177

Recebido em 10 de julho de 2018. Aceito em 20 de maio de 2020. 